\title{
PRODUÇÃO DE GELEIA REAL POR ABELHAS AFRICANIZADAS EM MOSSORÓ, RIO GRANDE DO NORTE, BRASIL
}

\author{
D. S. PEREIRA* , C. S. PAIVA, A. R. A. MENDES, J. S. BATISTA e P. B. MARACAJÁ \\ Instituto Federal de Educação, Ciência e Tecnologia do Rio Grande do Norte, Pau dos Ferros-RN, Brasil \\ santiagoesam@gmail.com*
}

Artigo submetido em junho/2013 e aceito em setembro/2015

DOI: $10.15628 /$ holos.2015.1478

\section{RESUMO}

Este trabalho foi realizado com o intuito de avaliar a produção de geleia real de abelhas africanizadas com a utilização de diferentes concentrações de água de coco no substrato-base das larvas. $O$ experimento foi realizado durante o mês de agosto de 2010 na Fazenda Experimental da UFERSA, Mossoró-RN. Para produção da geleia real foi utilizado o método Doolittle, utilizando-se cúpulas de acrílico de cor laranja. Cada cúpula recebeu $300 \mu \mathrm{l}$ de solução com geleia real (GR). Foram utilizadas 03 colmeias mini-recria modelo Ribeirão Preto. Os tratamentos testados constaram de solução de GR diluída em água de coco nas seguintes concentrações: $25 \%$ de GR; $50 \%$ de GR; e $75 \%$ de GR. Cada parcela foi composta de 20 cúpulas, sendo contabilizadas apenas as cúpulas com larvas aceitas pelas operárias para o cálculo das variáveis: PA - Percentual de aceitação de larvas; PL - Peso das larvas; PGR - Produção por cúpula de GR; GRT Produção de Geleia Real total. Os dados foram analisados utilizando-se ANOVA em blocos casualizados com 03 repetições, e os tratamentos também foram comparadas por analise de regressão linear com o auxilio do software $R$ versão 2.13.0. Verificou-se efeito significativo para a aceitação das larvas $(P>0,01)$ e a variável produção de geleia real por tratamento $(P>0,05)$, o peso das larvas, submetidos aos tratamentos, não mostrou efeito significativo. Houve influencia da concentração de substrato ofertado às larvas transferidas na aceitação das mesmas pelas operárias e na produção de geleia real. Conclui-se que o uso do substrato com geleia real influencia no índice de aceitação e sobrevivência das larvas e que o uso da água de coco na diluição da geleia real apresentou resultados satisfatórios.

PALAVRAS-CHAVE: Água de coco; Apis mellifera L.; Geleia real; Rio Grande do Norte

\section{ROYAL JELLY PRODUCTION BY AFRICANIZED BEES IN MOSSORO, STATE OF RIO GRANDE DO NORTE, BRAZIL}

\begin{abstract}
This study aimed at evaluating royal jelly production by Africanized bees by using different concentrations of coconut water in the larvae base substrate. The experiment was conduct throughout August 2010 at Experimental Farm of UFERSA in Mossoro, State of Rio Grande do Norte. Orange-colored cell cups were used to produce royal jelly through the Doolittle Method. Each cup had $300 \mu$ l of solution with royal jelly. For this purpose, 3 mini-hives model Ribeirão Preto were used. The evaluated treatments consisted of a solution of royal jelly dilute with coconut water in $25 \%, 50 \%$, and $75 \%$ of royal jelly. Each part was composed of 20 cups, and only the ones whose larvae were accepted by the worker bees were considered to calculate the variables: Percentage of larvae acceptance; Larvae weight; Royal
\end{abstract}

jelly production per cup; Total royal jelly production. The data were analyzed by using ANOVA in randomized blocks with 3 replications, and the treatments also compared by linear regression analysis with the use of $R$ software, version 2.13.0. It was verified a relevant effect for the larvae acceptance $(P>0.01)$ and royal jelly production per treatment $(P>0.05)$. The larvae weight submitted to treatments did not show significant effect. The concentration of substrate offered to the transferred larvae influenced in their acceptance by the worker bees and in the royal jelly production. It is concluded that the use of the substrate with the royal jelly influences the larvae acceptance and survival, and that the use of coconut water to dilute royal jelly presented satisfactory results.

KEYWORDS: Apis mellifera L.; Coconut water; Royal jelly; State of Rio Grande do Norte 


\section{INTRODUÇÃO}

A colônia de abelhas se perpetua por meio de sua renovação, sendo a rainha responsável pela sobrevivência e continuidade da colônia e da espécie (SILVA, 2000). A rainha não procura a sua própria alimentação, mas recebe essencialmente um alimento especial segregado pelas glândulas alimentares das operárias (SEGEREN, 2004).

A geleia real é secretada em pequena quantidade pelas glândulas hipofaringeanas e mandibulares para alimentar as larvas de abelhas operárias e de zangão até o terceiro dia de vida e alimentação da rainha durante toda a vida larvária e adulta (HAYDAK, 1970). A geleia real é uma secreção cremosa, sintetizada e secretada pelas glândulas mandibulares e hipofaringeanas das abelhas nutrizes entre o quinto e o $15^{\circ}$ dia de vida (TOLEDO et. al., 2010). É durante esta fase que as glândulas possuem completo desenvolvimento e secretam proteínas essenciais que fazem parte da alimentação de todas as crias e a rainha (REMBOLD et al., 1974; TAKENAKA e KAATZ, 1987; HRASSNIGG e CRAILSHEIM, 1998; CRAILSHEIM, 1991; SCHIMITZOVÁ et al., 1998).

Para sua síntese, as abelhas exigem carboidratos, vitaminas, ácidos graxos, minerais, aminoácidos essenciais, os quais são obtidos em condições naturais mediante a coleta de néctar e pólen (HERBERT JUNIOR, 1997).

A rainha alimenta-se com geleia real tanto na fase larval como adulta. A geleia real é responsável pelo desenvolvimento do aparelho reprodutivo da rainha, por sua longevidade. De acordo com a quantidade de geleia real fornecida, às rainhas apresentarão maior peso corporal ao nascer, maior número de ovaríolos e diâmetro de espermateca, quando comparadas com as mais leves (ALBARRACíN et. al, 2006; SOUZA et al., 2000).

A geleia real pode ser obtida com relativa facilidade e sua produção pode ser estendida o ano todo, sendo uma excelente opção para os apicultores nos períodos entre floradas e em regiões canavieiras onde o mel produzido possui características organolépticas com pouca aceitação comercial (NOGUEIRA-COUTO, 1991; GARCIA et al., 2000; QUEIROZ et al., 2001).

O processo para produção de geleia real é onerosa, tanto para as abelhas como para o produtor (HAYDAK, 1970), portanto, faz-se necessária a realização de pesquisas que objetivem minimizar os custos sobre o desenvolvimento e produção das colônias. O uso de água de coco na diluição da geleia real para a indução a aceitação das larvas transferidas para cúpulas artificiais pelas abelhas operárias, tem mostrado resultados positivos e satisfatórios, uma vez que por ser um produto oriundo de um minucioso sistema de produção, é caro, e sua diluição se apresenta como uma redução de custos no sistema de produção de rainhas e geleia real (MEDEIROS, 2007; MEDEIROS et. al., 2011; PEREIRA et. al., 2010 a, b; OLIVEIRA, 2007 a,b; OLIVEIRA et. al. 2007 a, b). Na produção de rainhas, a água de coco tem sido utilizada por pesquisadores e apicultores há algum tempo, no entanto, o seu uso não foi relatado anteriormente no meio científico para produção de geleia real (PEREIRA et. al., 2010 b).

\subsection{MÉTODO DOOLITTLE}

Para DOOLITTLE, (1889), o método "Doolittle" caracteriza-se por controlar o número de realeiras por recria, tendo como base a transferência de larvas para uma realeira artificial chamada 
de cúpula que são introduzidas em uma colmeia recria com rainha em plena postura. De acordo com Souza (1998), depois de seu desenvolvimento, passou a ser o método comercial de produção de geleia real e rainhas, mais exploradas no mundo.

Os princípios gerais de uma colônia Iniciadora-Terminadora de rainhas virgens, com postura plena de uma rainha fecundada foram descritos por Laidlaw (1979), Laidlaw \& Page (1997), e Laidlaw (1998), sendo o método comumente utilizado para produzir geleia real ou rainhas comercialmente.

Até a data da publicação do método Doolittle, não havia transferência de larvas ou realeiras artificiais (cúpulas), e eram utilizados até três colméias como recrias (uma iniciadora, uma de desenvolvimento e outra terminadora de realeiras) para a produção de geléia real ou rainhas (LAIDLAW JR., 1998).

Silveira Neto (2011), concluiu que na produção de geleia real por recria, deve ser dada preferência por recrias menores como as mini recrias, pois estas têm o manejo mais fácil em relação às outras e necessitam de um número menor de colmeias apoio para a sua manutenção.

De modo geral, a literatura especializada cita que, em abelhas do gênero Apis, a coleta de geléia real se dá em torno de 72 horas após ocorrida a transferência da larva. No entanto, isto pode estar relacionado, principalmente, com o local e a época em que ocorre a atividade, o que provavelmente determina variações importantes na produção de geléia (SANTOS e MESSAGE, 1980; WIESE, 1989; CORNEJO et al., 1970).

Queiroz et. al. (2011), informou que nas condições de Regiões de Semiárido no Sertão de Pernambuco, houve uma maior deposição de geléia real nas cúpulas artificiais entre o período de 54 a 72 horas após a transferência das larvas (enxertia).

Assim, o objetivo deste trabalho é identificar níveis de produção de geléia real, avaliando os efeitos da concentração de geléia real em água de coco (Cocos nucifera) oferecida às larvas no momento da transferência, sobre, a aceitação das larvas e a produção de geleia real em colônias de abelhas africanizadas (Apis mellifera L.).

\section{MATERIAL E MÉTODOS}

\subsection{LOCAL}

O presente experimento foi conduzido entre os dias 2 e 5 de agosto de 2010 no CETAPIS (CENTRO TECNOLOGICO DE APICULTURA E MELIPONICULTURA), nas dependências da Fazenda Experimental RAFAEL FERNANDES, "Campus" da UFERSA - Universidade Federal Rural do Semiárido, em Mossoró, estado do Rio Grande do Norte, Brasil. Nas seguintes coordenadas geográficas: Latitude S 503'44,2"; Longitude W 37'24'09,2"; e Altitude 92 metros.

O município de Mossoró-RN está inserido na região do semi árida nordestino, que segundo a classificação climática de Köppen-Geiger é do tipo BSw'h', ou seja, Semiárido quente com chuvas de outono e temperaturas médias mensais superiores a $18^{\circ} \mathrm{C}$. 


\subsection{Técnicas Empregadas}

Foram utilizadas três mini-recrias modelo Ribeirão preto, como colônias "iniciadorasterminadoras" compostas por um ninho e um núcleo sobreposto, separados por uma tela excluidora. No ninho, posicionado na parte inferior, mantiveram-se nove quadros. No núcleo foram mantidos três quadros mais um quadro porta cúpulas.

\subsection{REFORMA DAS RECRIAS}

O critério de seleção para as colônias "iniciadoras-terminadoras" foi o alto índice populacional das colônias. As colméias que apresentaram maior indicativo de ovos, larvas, cria fechada e abelhas operárias, bem como mel e pólen armazenados, foram selecionadas e preparadas.

No núcleo superior foi disposto um quadro com mel, um quadro com pólen, e um quadro com cria madura (15 - 19 dias), sendo o quadro porta cúpulas posicionado entre o quadro com pólen e o de cria. O quadro porta cúpulas possuía três barrotes transversais removíveis para fixação de sessenta cúpulas de acrílico, sendo vinte cúpulas localizadas no barrote de cima, vinte no meio, e vinte no barrote de baixo. As cúpulas utilizadas foram de material plástico, de coloração amarelo esverdeado, medindo 9,0 $\mathrm{mm}$ de diâmetro e 11,0 $\mathrm{mm}$ de profundidade, JZ-BZ.

\subsection{ALIMENTAÇÃO ARTIFICIAL}

A reforma das colméias mini-recria para recebimento das cúpulas com as larvas foi realizado três dias antes da transferência. Todas as colmeias receberam $500 \mathrm{ml}$ de xarope de açúcar (50\%) diariamente a partir da reforma e fornecido até a coleta das realeiras. Nesta mesma oportunidade forneceu-se 400 gramas (quatrocentos) por colmeia mini recria, uma dieta energético-proteica, constituída por: pó de pólen (10\%), soja (30\%), mel (10\%), açúcar (50\%), e água.

\subsection{TRANSFERENCIA DAS LARVAS}

Foram utilizados 3 tratamentos: T1 - solução com três partes de água de coco e uma de geleia real ( $25 \%$ de GR); T2- solução com uma parte de água de coco e uma de geleia real (50\% de GR) ; T3- e, solução com uma parte de água de coco e três de geleia real (75\% de GR). Preparada a solução foi então realizado, com o auxilio de um micropipetador de precisão $100 \mu \mathrm{l}$, a deposição de $300 \mu \mathrm{l}$ das soluções, de cada tratamento, por cúpula.

O método, adaptado, utilizado para produção de geleia real, foi o proposto por Doolittle (1889).

As larvas foram obtidas de quadros de uma única colônia matriz. Foram retirados quadros de cria de da colmeia matriz e levados ao Laboratório de Produção de Rainhas. Durante o transporte estes quadros foram cobertos com pano limpo e úmido e manuseados cuidadosamente para que a qualidade das larvas fosse mantida até o momento da transferência.

Utilizaram-se larvas com idade até 24 horas sendo transferidas para as realeiras artificiais com auxílio de uma agulha chinesa. As larvas, nos alvéolos dos quadros, foram distribuídas 
aleatoriamente nas cúpulas dos três tratamentos, cada barrote com 20 cúpulas consistiu em uma parcela do tratamento sendo os mesmos dispostos aleatoriamente no quadro porta cúpulas, e cada quadro distribuído aleatoriamente nas três colmeias mini recria. Ao todo foram realizadas 180 transferências de larvas em 3 mini-recrias.

\subsection{PRODUÇÃO DE GELÉIA REAL}

Seguiu-se a metodologia mais eficiente utilizada por Queiroz et.al. (2001), coletando-se os quadros no intervalo entre 54 e 72 horas.

Após aproximadamente 63 - 64 horas após a transferência, os quadros porta cúpulas com as realeiras foram retirados das mini-recrias e levadas para analise. Com o auxilio de uma balança de precisão 0,0001 g foram pesadas as larvas e a geléia real por tratamento. Os parâmetros estudados foram: porcentagem de aceitação (PA); peso das larvas ( $P L)$, e produção da geléia real por tratamento (GRT).

Os dados foram analisados por meio de Análises de Variância em Blocos Inteiramente Casualizados no software $R$ versão 2.15.0. Os tratamentos também foram analisados por regressão linear, e as variáveis correlacionadas pelo coeficiente de Pearson.

\section{RESULTADOS E DISCUSSÃO}

\subsection{ANÁLISES ESTATÍSTICAS}

Após as análises estatísticas realizadas verificou-se efeito significativo para os tratamentos aceitação de larvas e produção de geléia real. Houve influencia da concentração de substrato ofertado às larvas transferidas no percentual de aceitação das mesmas pelas operárias $(P<0,01)$, sendo o percentual de aceitação proporcional ao aumento da concentração do substrato. A variável produção de geléia real, também apresentou efeito significativo $(P<0,05)$, já variável peso das larvas não mostrou efeito significativo (TABELA 01).

Tabela 01. Resumo da análise de variância para as variáveis: porcentagem de aceitação (PA); peso de larvas (PL); e produção de geleia real por tratamento (GRT). (Summary of analysis of variance for the variables: percentage of acceptance (PA), weight of larvae (PL), and production of royal jelly by treatment (GRT)).

\begin{tabular}{lllllll}
\hline & $\mathrm{PA}$ & $\mathrm{PL}$ & $\mathrm{PGT}$ & $\mathrm{QM}$ \\
\hline FV & $\mathrm{GL}$ & $\mathrm{QM}$ & $\mathrm{GL}$ & $\mathrm{QM}$ & $\mathrm{GL}$ & $9,4508^{*}$ \\
\hline Solução de GR & 2 & $0,0295^{* *}$ & 2 & $0,5972^{\text {ns }}$ & 2 & 0,9696 \\
ERRO & 4 & 166,67 & 4 & 0,0916 & 4 & 65,12 \\
\hline CV (\%) & 54,39 & \multicolumn{5}{c}{78,18} \\
\hline \multicolumn{7}{c}{ *Significativo a 5\% (P<0,05); **Significativo a 1\% (P<0,01). }
\end{tabular}


Pode-se atribuir ao alto Coeficiente de Variação, (78,18\%), a variável não significativa PL- Peso das larvas.

A média de produção de cada tratamento por colmeia recria, para as variáveis analisadas foram: $53 \mathrm{mg}$ para o peso das larvas; 2,58g peso da geleia real por tratamento em cada colmeia; $215 \mathrm{mg}$ o peso da geleia real por cúpula (TABELA 02).

Tabela 02 - Médias gerais das variáveis observadas: PA - Percentual de aceitação; PL - Peso das larvas; e PGT Produção de geleia real por tratamento em cada colmeia. | 25\% de geleia real com água de coco; 50\% de GR com água de coco; e 75\% de GR com água de coco. (Overall averages of the observed variables: PA - Percentage of acceptance; PL - Weight of the larvae, and PGT - Production of royal jelly per treatment in each hive. | $25 \%$ royal jelly with coconut water, $50 \%$ coconut water with GR, GR and $75 \%$ coconut water).

\begin{tabular}{cccc}
\hline Tratamento & PA (\%) & PL $(\mathrm{mg})$ & PGT $(\mathrm{g})$ \\
\hline T1 - 25\% & 30 & 57 & 1,15 \\
T2 $-50 \%$ & 68 & 39 & 3,47 \\
T3 $-75 \%$ & 72 & 62 & 3,13 \\
\hline MÉDIA & $57 \%$ & $53 \mathrm{mg}$ & $2,58 \mathrm{~g}$ \\
\hline
\end{tabular}

Com a analise de regressão linear $(y=-0,04878 x+0,01283)$ foi observado uma mudança nos valores para o peso das larvas para cada acréscimo de $25 \%$ de geleia real na mistura, como também para a porcentagem de aceite com a regressão linear $(y=15 x+0,8333)$ sendo que ambos foram significativos a $5 \%$. A produção de geleia real por mini recria, com a regressão linear $(y=$ $0,5963 x+0,0397)$, também houve um aumento para cada acréscimo de $25 \%$ de geleia real, porém não sendo significativo (TABELA 03).

Tabela 03 - Resultados obtidos após analise de regressão linear nos pesos das larvas, porcentagem de aceite e da produção de geleia real por tratamento em relação à concentração de geleia real no substrato. (Results obtained after linear regression analysis in weight of the larvae accepted and the percentage of production of royal jelly by treatment over the concentration of royal jelly in the substrate).

\begin{tabular}{cccc}
\hline Concentrações GR & $25 \%$ & $50 \%$ & $75 \%$ \\
\hline Peso das larvas (mg) & 0,2718889 & 0,5925556 & 0,9132222 \\
Porcentagem de aceite (\%) & 35,83333 & 56,66667 & 77,50000 \\
Geléia real tot/trat/colmeia (g) & 1,588833 & 2,581333 & 3,573833 \\
\hline
\end{tabular}

Observou-se então que ocorreu um aumento significativo no índice de aceitação das larvas para cada acréscimo de $25 \%$ na concentração de GR no substrato. Isso pode ser explicado pelo possível aumento no consumo do substrato pela larva, proporcionando assim uma maior sobrevivência e aumentando o índice de aceitação.

Foram encontrados coeficientes de correlação fortemente positiva entre a porcentagem de aceitação das larvas e a produção total de geleia real ( $r$ : 0.925, P<0.01), (TABELA 04 - 05).

Tabela 04 - Resumo da analise de variância da regressão dos pesos das larvas e da produção de geleia real total. Peso de larvas (PL); Porcentagem de aceite; e produção da geleia real por tratamento (PGT). (Summary of analysis of variance of the regression weights of the larvae and the total production of royal jelly. Weight of larvae (PL); Percent accepted, and production of royal jelly by treatment (GRT)).

\begin{tabular}{lcccccc}
\hline \multicolumn{1}{c}{ FV } & $\mathrm{PL}$ & \multicolumn{3}{c}{$\mathrm{PA}$} & $\mathrm{PGT}$ \\
& $\mathrm{GL}$ & $\mathrm{QM}$ & $\mathrm{GL}$ & $\mathrm{QM}$ & $\mathrm{GL}$ & $\mathrm{QM}$ \\
\hline Soluções de GR & 1 & $0,61696^{*}$ & 1 & $2604,17^{*}$ & 1 & $5,9103^{\text {ns }}$ \\
ERRO & 7 & 1,13573 & 7 & 713,69 & 7 & 16,6921 \\
\hline \multicolumn{6}{l}{ *Significativo a } & $5 \%(\mathrm{P}<0,05)$.
\end{tabular}


Tabela 05 - Coeficiente de correlação de Pearson entre as médias das variáveis: PA - percentual de aceitação; PL peso das larvas; PGT - produção de geleia real por tratamento; e (Pearson correlation coefficient between the means of the variables: PA - percentage of acceptance; PL - weight of larvae; PGT - production of royal jelly by treatment).

\begin{tabular}{c|c|c|c}
$\mathrm{N}=03$ & $\mathrm{PA}$ & $\mathrm{PL}$ & $\mathrm{PGT}$ \\
\hline $\mathrm{PA}$ & 1 & $-0,26439$ & $0,979 * *$ \\
\hline $\mathrm{PL}$ & & 1 & $-0,45706$ \\
\hline $\mathrm{PGT}$ & & & 1 \\
\hline
\end{tabular}

*Significativo para $\mathrm{P}<0,05 ; * *$ Significativo para $\mathrm{P}<0,01$

Esses resultados indicam que quanto maior é a porcentagem de aceitação, maior será a produção de geleia real por tratamento e por colmeia, corroborando com os resultados obtidos por Duran (1991), Garcia (1992), Levy et al. (1993), e Albarracin et al. (2006), mas discordando dos obtidos por Couto (1991). E quanto maior for à deposição de geleia real por realeira maior será a produção total de geleia real (FIGURA 01).

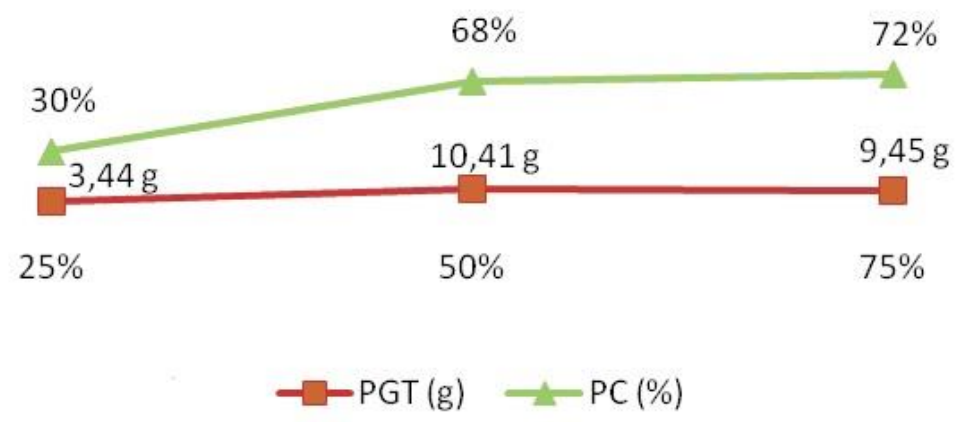

Figura 01 - Comparação da influencia do PC (percentual de aceitação) em PGT (produção de geleia real por tratamento). (Comparison of the influence of the PC (percentage of acceptance) PGT (royal jelly production per treatment).

\subsection{ACEITAÇÃO DAS LARVAS}

A aceitação de larvas encontradas neste estudo, nos tratamentos que utilizaram $50 \%$ e $75 \%$ de geléia real no substrato, foram superiores aos observados por Van Toor \& Littlejonh (1994) e Toledo, et. al. (2010) que encontraram 33,15 \% e 29,20\% de aceitação de larvas, respectivamente. E semelhantes aos encontrados por Silveira Neto (2011), que obteve $71,88 \% \pm 2,5516$ de aceitação no estado do Ceará.

De posse dos resultados, contatou-se que a concentração de geleia real influenciou no índice de aceitação. Corbela (1985), afirma que o sucesso na taxa de aceitação das larvas pelas operárias para se transformarem em rainhas, além da dependência das variáveis climáticas, dependem também da idade das larvas transferidas bem como da habilidade manual do autor da transferência, pois além do cuidado de não danificar a larva durante a transferência da mesma do favo para a cúpula contendo geleia real, quanto mais nova for à larva maior é o sucesso da transferência.

Pereira et. al. (2012) apresentou que a produção de rainhas decaiu em função do período do ano, do período chuvoso à entressafra no Rio Grande do Norte, encontrando índices máximos de $77 \%$ e mínimos de $37,50 \%$. 
Oliveira (2007 a) e Oliveira et al., (2007 a, b) desenvolveram um estudo similar a este, utilizando água de coco na diluição de geleia real, e encontraram que quanto maior a concentração de geleia real na solução, maior seria a aceitação de larvas para produção de abelhas rainha. Medeiros $(2007,2011)$, reafirma isso comparando a aceitação frente aos substratos: Geleia Real pura e Água de Coco. Tendo encontrado que as abelhas optaram cuidar e alimentar as larvas que tinham geleia real pura como substrato com $80 \%$, e a água de coco apresentou um baixo percentual de $20 \%$ de aceitação.

Pereira et al. (2010_a), analisando a influencia do volume do substrato (solução de água de coco e geleia real (50\%) fornecido às larvas no percentual de aceitação em Mossoró-RN, encontrou que o volume (300 $\mu \mathrm{l}$ ) proporcionou uma média estimada de 92,735\%, para (100 $\mu \mathrm{l}) 56,725 \%$, e no tratamento em que o substrato foi ausente $38,81 \%$. A utilização da solução de geleia real foi mais eficiente na aceitação das larvas, sendo que a utilização de 100 e $300 \mu \mathrm{l}$, perfizeram juntos $90 / 120$ das larvas transferidas nos dois tratamentos, ou $75 \%$ do total.

\subsection{PESO DAS LARVAS}

Apesar dos pesos das larvas não diferirem entre os tratamentos observou-se uma tendência de média de peso maior para as larvas das cúpulas do tratamento - T3, e a deposição de geleia real por cúpula foi maior nos tratamentos T2 $(0,248 \mathrm{~g})$ e T3 $(0,220 \mathrm{~g})$.

A variável peso das larvas apresentou média de $53 \mathrm{mg}$, sendo as médias dos tratamentos: T1 - 57 mg; T2 - 39 mg; e T3 - 62 mg. O índice de aceitação das larvas apresentou uma média de $57 \%$, e variou entre 30 e $72 \%$. Os resultados de peso das larvas deste trabalho são semelhantes aos encontrados por (QUEIROZ, 2001) que observou peso médio de larvas 56,76 mg no município de Petrolândia. Os resultados obtidos foram ligeiramente superior aos observados por Garcia (1992), que encontrou peso médio da larva de $49,90 \mathrm{mg}$, e muito superiores aos relatados por Silveira Neto (2011), que encontrou peso de larvas de 18,7 $\pm 1,1 \mathrm{mg}, 48$ horas após a transferência das larvas para as cúpulas.

Também ocorreu um aumento no peso das larvas para cada acréscimo de $25 \%$ na concentração de GR no substrato. Com o aumento da concentração de geleia real no substrato, consequentemente a larva terá uma maior quantidade de geleia real para o consumo, proporcionando um maior peso, tendo em vista que a geleia real é um alimento completo com diversos nutrientes. Segundo Souza et al., (2000) as rainhas que apresentam maior peso corporal ao nascer, também apresentam maior número de ovaríolos e maior diâmetro de espermateca, quando comparadas com as mais leves.

De acordo com os resultados encontrados no presente estudo o aumento da concentração de geleia real no substrato aumenta o peso da larva, com isso subtende-se que larvas mais pesadas darão origem a rainhas maiores, e por consequência rainhas com maior capacidade ovipositora.

\subsection{PRODUÇÃO DE GELÉIA REAL}

Os seguintes resultados de produção de GR por tratamento, somado as três colmeias, foram encontrados: T1- 3,436g; T2- 10,405g; T3- 9,39g. Obteve-se, ao todo, 23,22 gramas de geleia real, quando somado a produção nas três recrias utilizadas neste trabalho. 
Martinez et. al. (2006), em seu trabalho sobre produção de geleia real realizado em Ribeirão Preto-SP, encontrou uma produção por colmeia mini-recria entre 6,06 a 19,9g de GR, e uma média de aceitação das larvas transferidas de 63\%, variando entre 43 e $87 \%$. Silveira Neto (2011), no estado do Ceará, utilizando o método Doolittle, encontrou produção de geleia real total por colmeia mini-recria de 4,7084 $\pm 0,4822 \mathrm{~g}$.

Os resultados de aceitação das larvas transferidas às cúpulas e a produção de geleia real foram superiores aos obtidos em outros trabalhos com abelhas africanizadas (GARCIA \& NOGUEIRA-COUTO, 2005; TOLEDO e MOURO, 2005; GARCIA, 2005; ALBARRACIN, 2006; TOLEDO, 2010).

O alto índice de indivíduos, abelhas operárias, nas colméias pode ter influenciado nos resultados obtidos. McConnell (1935), afirma que uma colônia populosa é de grande importância para a produção de rainhas, qualquer que seja o método utilizado.

Entretanto, 0 tempo de 63 - 64 horas, utilizado para a coleta das larvas também mostrouse eficiente, concordando com os dados apresentados por LEVYet al. (1990), NUNES JR. et al. (1994), e BARBOSA \& MARTINHO (1994), que observaram maiores produções de geléia real, de abelhas Apis mellifera, em coletas efetuadas de 44 a 64 horas após a transferência das larvas. Já GARCIA (1992), trabalhando com abelhas africanizadas, relata que a extração da geléia real pode ser realizada em torno de 69 horas após a transferência da larva.

Alguns resultados aqui observados podem ter sido superiores a outros trabalhos, não apenas pela concentração de geleia real oferecida as larvas no momento da transferência, mas pelo conjunto de técnicas utilizado em todo o processo. E ainda pelo fato de estarmos trabalhando com um híbrido, abelha africanizada, que apresenta fenótipo e genótipo mais próximos de suas ascendentes africanas, por conta disto, o período de desenvolvimento larval deve ser menor que os 21 descritos para as abelhas da raça italiana pura (Apis mellifera ligustica).

É importante ressaltar que neste e nos demais trabalhos, discutidos neste artigo, que analisaram a concentração de geleia real e sua influencia na aceitação de larvas para produção de rainhas, dispuseram todos os tratamentos ao mesmo tempo nas recrias, tendo as abelhas operárias selecionado àquelas larvas, que estavam sobre o substrato mais palatavelmente parecido com geléia real.

Observando este aspecto, é necessária a repetição do experimento tomando-se cada colmeia recria como uma unidade de análise de um único tratamento. Deste modo, analisar-se-á, um resultado mais próximo da realidade na prática em campo, sobre a real aceitabilidade pelas abelhas africanizadas à diluição da geleia real no processo de produção de geleia real, uma vez que, o produtor necessita de informações precisas e práticas para a execução do manejo nos apiários do semiárido do nordeste brasileiro.

\section{CONCLUSÃO}

Concluiu-se que o uso do substrato com geleia real influencia no índice de aceitação e sobrevivência das larvas de acordo com o acréscimo na concentração de geleia real da solução; 
Constatou-se que o uso da água de coco na diluição da geleia real apresentou resultados satisfatórios no índice de aceitação e peso das larvas, e a diluição a partir de $50 \%$ de geleia real em água de coco, apresentou melhores resultados;

O aumento do percentual de aceitação de larvas influencia na produção de geleia real e por colmeia. Portanto de acordo com os resultados encontrados constatou-se que neste trabalho o uso da água de coco na solução conferiu uma maior produção de geleia real;

O intervalo de tempo, de 63 a 64 horas, para coleta das cúpulas após a transferência das larvas na produção de geléia real, mostrou resultados até então satisfatórios no semiárido brasileiro.

\section{REFERÊNCIAS}

1. ALBARRACÍN, V.N.; CUNHA FUNARI, S.R.; ROMERO ARAUCO, E.M.; OLIVEIRA ORSI, R de.. Aceitação de larvas de diferentes grupos genéticos de Apis mellifera na produção de abelhas rainhas. Arch. Latinoam. Prod. Anim. Vol. 14 (2): 33-41. 2006.

2. BARBOSA, S.B.P., MARTINHO, M.R. 1994. Produção de Geléia Real em abelhas Apis mellifera L. Caderno Ômega da Universidade Federal Rural de Pernambuco, Série Zootecnia, Recife, 2:73-80.

3. CORBELLA, 1985. Aspectos adaptativos e ecológicos de aceitação de larvas transferidas nas abelhas Apis mellífera $L$. como subsídios para o melhoramento de rainhas e produção de geleia real. Tese de Doutorado. FMRP-USP, 109 pp.

4. CORNEJO, L.G., BARTOLOMÉ, R., ITZCOVICH, B. Costa de production de jalea real, período de 1969/70, en Argentina. In: CONGRESSO BRASILEIRO DE APICULTURA, 1, 1970, Florianópolis. Anais ... Florianópolis: Associação Catarinense de Apicultura, 1970. p.210-216.

5. COUTO, R. H. N. Produção de alimento e cria em colmeias de Apis mellifera infestadas com varroa jacobsoni em regiões canavieiras. Jaboticabal. SP.. Tese (Livre Docência em apicultura)Faculdade de Ciências Agrárias e Veterinárias. Universidade Estadual Paulista. 131 p. 1991.

6. CRAILSHEIM, K. Interadult feeding of jelly in honeybee (Apis mellifera L.) colonies. Journal of Comparative Physiology B, v. 161, p. 55-60, 1991.

7. DOOLITTLE, G.M. Scientific Queen-Rearing. Chicago, Illinois, USA: Thomas G.Newman \& Son. 1889.

8. DURAN, J. E. T.. Estudo de variáveis ambientais e do ácaro Varroa jacobsoni na produção de geleia real em colmeias de Apis mellifera. Jaboticabal. SP. Dissertação (Mestrado em Zootecnia)-Faculdade de Ciências Agrárias e Veterinárias. Universidade Estadual Paulista. 97 p. 1991.

9. GARCIA, R. C.. Produção de geleia real desenvolvimento de colonias e de glândulas hipofarinfeanas em abelhas Apis mellifera Italianas e seus híbridos Africanizados em fecundação natural e instrumental. Jaboticabal. SP. Dissertação (Mestrado em Zootecnia)Faculdade de Ciências Agrárias e Veterinárias. Universidade Estadual Paulista. 239 p. 1992.

10. GARCIA, R.C.; MALERBO-SOUZA, D.T.; NOGUEIRA-COUTO, R.H. Cúpulas comerciais para produção de geleia real e rainhas em colméias de abelhas Apis mellifera. Scientia Agrícola, v. 57, n. 2, p. 367-370, 2000. 
11. GARCIA, R.H.C.; NOGUEIRA-COUTO, R.H. Produção de geleia real por abelhas Apis mellifera italianas, africanizadas e descendentes de seus cruzamentos. Acta Scientiarum Animal Science, v. 27, n. 1, p. 17-22, 2005.

12. HAYDAK, M H. Honey bee nutrition. Annual Review of Entomology, v. 15, p. 143- 156, 1970.

13. HERBERT JUNIOR., E. W. Honey bee nutrition. In: GRAHAM, J. M. (Ed.). The hive and the honey bee. Hamilton: Dadant and Sons, 1997. p. 197-233.

14. HRASSNIGG, N.; CRAILSHEIM, K. Adaptation of hypopharyngeal gland development to the brood status of honeybee (Apis mellifera L.) colonies. Journal of Insect Physiology, n. 44, p. 929-939, 1998.

15. LAIDLAW H. H. JR. Criação Contemporânea de Rainhas. Canoas: La Salle, 1998, 8-14p.

16. LAIDLAW, H.H. JR. \& PAGE, R.E. JR. Queen Rearing and Bee Breeding. Cheshire, Conneticut, USA: Wicwas Press. 1997.

17. LAIDLAW, H.H. JR. Contemporary Queen Rearing. Hamilton, Illinois, USA: Dadant \& Sons. 1979.

18. LEVY, P.S.; SILVA, R. M.B.; PARANHOS, B.A.J. et al. Influência do tempo entre a transferência das larvas e a colheita sobre a produção de geleia real de abelhas africanizadas (Apis mellifera). Boletim de Indústria Animal, v. 50, n. 2, p. 113-117, 1993.

19. MARTINEZ, O.A.; ZULLO, A.S.; MORENO, V. \& SOARES, A.E.E..Produção de geleia real com abelhas africanizadas - Uma alternativa para o pequeno apicultor. Anais ... XVI CBA. 2006.

20. MCCONNELL H. Queen rearing. Am. Bee J. v. 75, n. 7, p. $332-333.1935$.

21. MEDEIROS, P.V.Q. de.. Substratos Alternativos à Geleia Real em Cúpulas para Produção de Abelhas Rainha de Apis mellifera spp. Monografia (Graduação em Agronomia) - UFERSA. 2007.

22. MedeIROS, P.V.Q. de.; PEREIRA, D.S.; MARACAJÁ, P.B.; SAKAMOTO, S.M.. PRODUÇÃO DE ABELHAS RAINHA Apis mellifera spp. (Africanizadas) NO SEMI ÁRIDO CEARENSE, BRASIL. Revista Verde de Agroecologia e Desenvolvimento Sustentável. V.6 ., N. 5. 2011.

23. NOGUEIRA-COUTO, R.H. Produção de alimento e cria em colméias de Apismellifera infestadas com Varroa jacobsoni, em regiões canavieiras. Tese (Livre Docência em Apicultura) - Faculdade de Ciências Agrárias e Veterinárias - Universidade Estadual Paulista, Jaboticabal. 131p. 1991.

24. NUNES JR., R.C., BARBOSA, S.B.P., QUEIROZ, M.L. Produção de geléia real em abelhas Apis mellifera $L .$, em diferentes momentos de coleta. In: SOCIEDADE BRASILEIRA DE ZOOTECNIA, 31, 1994, Maringá. Anais... Maringá: SBZ, 1994. p.593.

25. OLIVEIRA, D. S. de ; VIEIRA; GRAMACHO . Água de côco como substituto da geleia real na produção artificial de abelhas rainhas africanizadas (Apis mellifera L.). In: IV CONBAP Congresso Baiano de Apicultura, Anais..., Porto Seguro. 2007 a.

26. OLIVEIRA, D. S. de ; VIEIRA ; GRAMACHO . Influência da concentração de geleia real para produção de abelhas rainhas africanizadas, Apis mellifera L. (HYMENOPERA: APIDAE). In: IV CONBAP - Congresso Baiano de Apicultura, Anais... Porto Seguro. 2007 b.

27. OLIVEIRA, D.S. de . Substitutos da geleia real para produção de abelhas rainhas africanizadas, Apis melifera scutellata (HYMENOPERA: APIDAE). In: IV Seminário de pesquisa FTC. Anais..., 
Salvador, 2007

b.

28. OLIVEIRA, D.S. de.. Subsídios para melhoria de técnicas de criação de abelhas rainhas africanizadas Apis mellifera L. (HYMENOPERA: APIDAE). Monografia (Graduação em Ciências Biológicas) - Faculdade de Tecnologia e Ciências. 2007 a.

29. PEREIRA, D.S.; BARBOSA, G.R.; PAIVA, C. da S.; GRAMACHO, K.P.; GONÇALVES, L.S.. Influencia do Uso de Diferentes Volumes de Solução de Geleia Real na Aceitação de Larvas para Produção de Abelhas Rainha Africanizadas. In: $X$ CONGRESSO IBEROLATINOAMERICANO DE APICULTURA. Anais... CD-ROM. Natal-RIO GRANDE DO NORTE/BRASIL. Outubro, 2010 a.

30. PEREIRA, D.S.; BARBOSA, G.R.; PAIVA, C. da S.; GRAMACHO, K.P.; GONÇALVES, L.S.. Produção de Geleia Real em Colméias de Abelhas Africanizadas em Mossoró-RN. In: II SEMINÁRIO CEARENSE DE APICULTURA. Anais... CD-ROM. Crato-CEARÁ/BRASIL. Dezembro, 2010 b.

31. PEREIRA, D.S.; PAIVA, C. da S.; Barbosa, G.R.; MARACAJÁ, P.B.. Produção de Rainhas (Apis mellifera L.), e Taxa de Fecundação Natural em Quatro Municípios do Nordeste Brasileiro. REVISTA VERDE DE AGROECOLOGIA E DESENVOLVIMENTO SUSTENTÁVEL, VOL. 7, NO 5. 2012.

32. QUEIROZ, M.L.; BARBOSA, S.B.P.; AZEVEDO, M. Produção de geleia real e desenvolvimento de abelhas Apis mellifera, na região semiárida de Pernambuco. Revista Brasileira de Zootecnia, v. 30, n. 2, p. 449-453, 2001.

33. REMBOLD, H.; LACKNER, B.; GEISTBECK, I. The chemical basis of honeybee, Apis mellifera, caste formation, partial purification of queen bee determination from royal jelly. Journal of Insect Physiology, v. 20, p. 307-314, 1974.

34. SANTOS, J.J., MESSAGE, D. Utilização de mini-recrias para produção de geléia real. In: CONGRESSO BRASILEIRO DE APICULTURA, 5, CONGRESSO LATINO-IBERO-AMERICANO DE APICULTURA, 3, 1980, Viçosa. Anais... Viçosa: Confederação Brasileira de Apicultura, 1980. p.307-11.

35. SCHIMITZOVÁ, J.; KLAUDINY, J.; ALBERT, S.; et al. A family of major royal jelly proteins of the honeybee Apis mellifera L. Cellular and Molecular Life Sciences, v. 54, p. 1020-1030, 1998.

36. SEGEREN, P.. A apicultura nas regiões Tropicais. Fundação Agromisa, Wageningen, 2004.

37. SILVA, E.C. A.. Avaliação da eficiência de técnicas de remessa postal e das condições da colmeia na aceitação e fecundação natural de rainhas de abelhas africanizadas (Apis mellifera L.). Rio Claro. SP. Tese (Doutorado em Ciências Biológicas)- Instituto de Biociências. UNESP. 92p. 2000.

38. SILVA, E.C.A.; SILVA, R.M.B.; MORETI, A.C.C.C.; ALVES, M.L.T.M.F. Cúpulas de diferentes materiais e cores para produção de geleia real usando abelhas africanizadas (Apis mellifera L.). In: CONGRESSO BRASILEIRO DE APICULTURA, 10., 1996. Anais. Teresina: Confederação Brasileira de Apicultura, p.384. 1996.

39. SILVEIRA NETO, A. A.. Avaliação de Quatro Métodos de Produção de Geléia Real e Rainhas de Apis mellifera no estado do Ceará. Dissertação (Mestrado em Zootecnia) - Centro de Ciências Agrárias / Universidade Federal do Ceará (UFC). 77p. 2011.

40. SOUZA, D. C.; SOARES, A. E. E., SILVA NETO, E.. Relação entre o peso da rainha ao emergir e o volume da realeira. In: CONGRESSO BRASILEIRO DE APICULTURA. Florianópolis. Anais... Florianópolis: CBA. (CDRoom). 13. 2000.

41. SOUZA. D. C. Manejo de Rainhas. In: CONGRESSO BRASILEIRO DE APICULTURA, 12., 1998. 
Anais... Salvador: CBA, 1998. CD 4ạ Edição.

42. TAKENAKA, T.; KAATZ, H.H. Protein synthesis by hypopharyngeal glands of worker honey bees. In: EDER, J.; REMBOLD, H. (eds). Chemistry and biology of social insects. München: Peperny, p. 166-167. 1987.

43. TOLEDO, V.A.A.; MOURO, G.F. Produção de geleia real com abelhas africanizadas selecionadas cárnicas e híbridas. Revista Brasileira de Zootecnia, v. 34, n. 6, p. 2085-2092, 2005.

44. TOLEDO, V.A.A.; NEVES, C.A.; ALVES, E.M.; OLIVEIRA, J.R.; UVOLO-TAKASUSUKI, M.C.C.; FAQUINELLO, P.. Produção de geleia real em colônias de abelhas africanizadas considerando diferentes suplementos proteicos e a influência de fatores ambientais. Acta Scientiarum. Animal Sciences. Maringá, v. 32, n. 1, p. 101-108, 2010.

45. VAN TOOR, R. F.; LITTLEJONH, R. P. Evaluation of hive management techniques in production of royal jelly by honey bees (Apis mellifera) in New Zealand. Journal of Apicultural Research, v. 33, n. 3, p. 160-166, 1994.

46. WIESE, H. Nova apicultura. Porto Alegre: Livraria e Editora Agropecuária Ltda. . 6.ed. 1989. 